
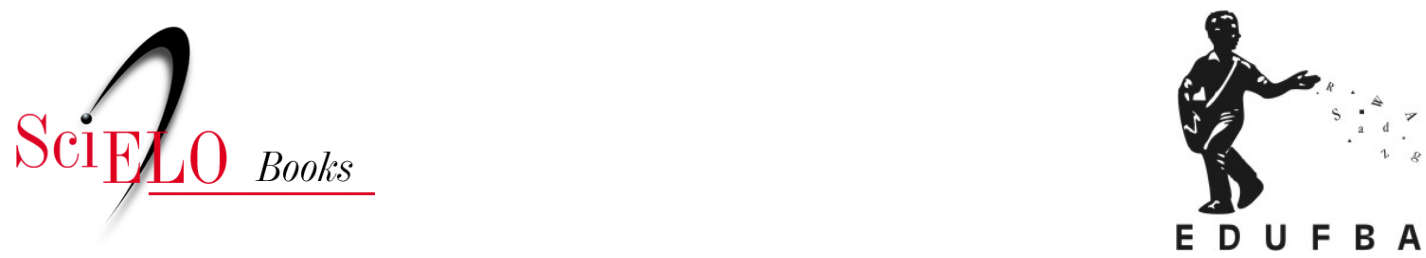

\title{
Parte I - Cultura e Consumo Alimentar Dinâmicas Culturais na Alimentação: da Formação das Cozinhas à Construção das Identidades Nacionais de Brasil e Portugal
}

\author{
Talita Prado Barbosa Roim
}

\section{SciELO Books / SciELO Livros / SciELO Libros}

ROIM, T. P. B. Dinâmicas Culturais na Alimentação: da Formação das Cozinhas à

Construção das Identidades Nacionais de Brasil e Portugal In: CARVALHO, M. C. V. S., KRAEMER, F. B., FERREIRA, F. R., and PRADO, S. D., eds. Comensalidades em trânsito [online]. Salvador: EDUFBA, 2020, pp. 41-65. Sabor metrópole series, vol. 11. ISBN: 978-655630-177-8. http://doi.org/10.7476/9786556301778.0003.

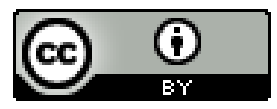

All the contents of this work, except where otherwise noted, is licensed under a $\underline{\text { Creative }}$ Commons Attribution 4.0 International license.

Todo o conteúdo deste trabalho, exceto quando houver ressalva, é publicado sob a licença Creative Commons Atribição 4.0.

Todo el contenido de esta obra, excepto donde se indique lo contrario, está bajo licencia de la licencia Creative Commons Reconocimento 4.0. 


\title{
DINÂMICAS CULTURAIS NAALIMENTAÇÃO DA FORMAÇÃO DAS COZINHAS À CONSTRUÇÃO DAS IDENTIDADES NACIONAIS DE BRASIL E PORTUGAL ${ }^{1}$
}

\author{
TALITA PRADO BARBOSA ROIM
}

\section{INTRODUÇÃO}

No mundo em que vivemos atualmente, cada vez mais globalizado e conectado, debates sobre regionalismos, nacionalismos e identidades nacionais têm retornado ao campo de debates das ciências sociais e humanas a fim de pensar sobre diferentes rumos políticos e caminhos econômicos que os diferentes países, em suas diferentes conjunturas, têm tomado como medidas de políticas internacionais, bem como de políticas públicas para o desenvolvimento interno e externo dessas nações, como por exemplo, alimentação adequada e soberania e segurança alimentar e nutricional (SSAN).

1 Esse texto faz parte da pesquisa financiada pelo Programa Nacional de Pós-Doutorado da Coordenação de Aperfeiçoamento de Pessoal de Nível Superior (PNPD-CAPES) no Programa de Pós-Graduação em Antropologia Social da Universidade Federal de Goiás. 
Discutir tais temas tornam-se necessários na medida em que movimentos políticos e sociais que estariam aparentemente superados, retornam à baila com força e intensidade nas posições conservadoras que alguns países centrais dentro política internacional vêm aderindo e reafirmando.

A partir dessa realidade que nos apresenta, justifica-se a escolha do tema da formação de Estados-nações e construção de identidades e cozinhas nacionais. Entender os processos pelos quais Brasil e Portugal passaram para chegar às suas configurações sociais atuais é importante para refletir e analisar o tempo presente. De modo que, voltar à história do Brasil, à formação do pensamento social, aos projetos de formação da nação brasileira e de identidade nacional se fazem úteis para rever e rediscutir "o que faz o brasil, Brasil”. (DAMATTA, 1986) ${ }^{2}$

Os projetos políticos de configuração de nação são construções sociais mediadas pelos interesses políticos e culturais de cada período e contexto sócio-histórico. Dentro de uma perspectiva antropológica, baseando-se em Benedict Anderson (2008) tomamos como conceito “[...] a seguinte definição de nação: uma comunidade política imaginada - e imaginada como sendo intrinsecamente limitada e, ao mesmo tempo, soberana”. (ANDERSON, 2008, p. 31)

Nesse sentido, as comunidades se distinguem não porque são falsas ou autênticas, mas porque têm estilos diferentes de serem imaginadas, pensadas e, também de serem percebidas e vividas. Para Anderson (2008), a nação é imaginada como soberana porque o conceito nasce no Iluminismo, momento histórico em que revoluções estavam ocorrendo na Europa, questionando e destruindo a legitimidade dos reinos dinásticos hierárquicos de ordem divina. Dessa maneira, a ideia do que seja nação é imaginada como uma comunidade soberana e seus aspectos legitimadores.

Assim, a soberania é conseguida por meio do Estado e sua consolidação seja pela via política (normatizações, leis, regras sociais), seja pela via cultural (língua, costumes, vestimentas, cozinha). São os elementos cotidianos legitimados pelo Estado que permitem enaltecer o que é diferente e específico em cada nação e o que lhes é motivo de orgulho, formando identidades.

2 Parafraseando a obra do autor Roberto DaMatta O que faz o brasil, Brasil? (publicado originalmente em 1986), especialmente na diferenciação que o autor faz ao conceituar alimento e comida. 'O alimento é algo universal e geral, diz respeito a todos os seres humanos [...]. Comida se refere a algo costumeiro e sadio, alguma coisa que ajuda a estabelecer uma identidade, definido, por isso mesmo, um grupo, uma classe, ou pessoa'. (DAMATTA, 1991, p. 55) 
Os frutos culturais do nacionalismo - a poesia, a prosa, a música, artes plásticas - mostram esse amor com muita clareza, e em milhares de formas e estilos diversos. Por outro lado, como é difícil encontrar frutos nacionalistas semelhantes expressando medo e aversão. (ANDERSON, 2008, p. 200)

Para ser possível analisar a constituição da cozinha brasileira e a eleição dos ingredientes e pratos típicos que a compõem, proponho a reflexão sobre a relação entre Brasil e Portugal, em uma perspectiva teórica que nos permita relacioná-las com as noções de colonizador e colonizado dentro de um processo de trocas culturais, em que os dois países se envolvem mais intensamente entre o período histórico e político do processo de descolonização ao império, da independência à formação da república no Brasil e, consequentemente, seus desprendimentos e novos entrelaçamentos com a nação portuguesa.

Assim, proponho pensar na tríade - nação, alimentação e literatura relacionando-a com o resgate histórico do Brasil Imperial e de Portugal no período colonial, e suas representações em obras de literatura clássica - Eça de Queiros e Machado de Assis -, admitindo que em uma perspectiva antropológica é possível “[...] submeter conceitos preestabelecidos à experiência de contextos diferentes e particulares, assim ela [a antropologia] procura dissecar e examinar, para então analisar a adequação de tais conceitos”. (PEIRANO, 1990, p. 3, grifo nosso)

Diante de tal método pretende-se reconstruir os caminhos da formação da cozinha brasileira e da cozinha portuguesa como elementos fundadores de identidades nacionais, formulando uma ideia de nacionalidades construídas pelas diferenças. (HALL, 2004)

\section{LITERATURA, ALIMENTAÇÃO E FORMAÇÃO DE NAÇÃO}

O comportamento relativo à comida liga-se diretamente ao sentido de nós mesmos e à nossa identidade social, e isso parece valer para todos os seres humanos. (MINTZ, 2011, p. 31)

Portugal tem o papel de país civilizador no processo de desenvolvimento da nação brasileira, porém tal posição vai sendo trocada e muitas vezes invertida ao longo dos entrelaçamentos culturais e políticos com o 
Brasil. Os marcos históricos das trocas culturais aqui enfatizados se referem à chegada da corte portuguesa em 1808 e, a partir de então, o caminho percorrido para a independência (1889) e a formação da Primeira República brasileira (1889-1930).

As trocas culturais entre Brasil e Portugal são intensas, complexas, controversas e congregam situações pertinentes para a consolidação das duas nações, bem como suas identidades nacionais e reconhecimento enquanto países autônomos que, a partir de questões políticas desempenham aspectos importantes para concretização de suas cozinhas e, em consequência, dos projetos de legitimidade da nação.

Nos detemos nesse momento à análise de alguns aspectos da vida e obra de dois representantes da intelligentsia portuguesa e brasileira do período, ${ }^{3}$ tanto de Machado de Assis, eleito por alguns, mas discutidos por outros, ${ }^{4}$ como um dos intelectuais a formar o pensamento social genuinamente brasileiro; e Eça de Queirós, intelectual português que para além da obra literária, ocupou cargos políticos e teve relação direta com o Brasil via textos jornalísticos publicados em jornal do país.

Tais aspectos serão tratados nessa sessão a fim de criarmos caminhos possíveis para articular o que sugerimos como objetivo a ser discutido: formação de cozinhas nacionais como aspectos importantes na construção e consolidação de estados nacionais.

O objetivo é estudar os processos (ELIAS, 2011) de construção de identidades nacionais dos dois países sob o viés do cotidiano alimentar e a formação de suas cozinhas, buscando diferentes fontes de dados: literatura; ciência; documentos históricos; representações socioculturais. "A identidade nacional, como todo processo de construção de identidade, tem uma dimensão interna na qual se acentuam os traços de similaridades, ao mesmo tempo, uma dimensão externa, que define uma diferença em relação ao outro". (OLIVEIRA, 1990, p. 11-12)

3 Interseccionando o período histórico abordado nesse capítulo (1808 e 1930) com o período de vida e de morte de Eça de Queirós (1845-1900) e de Machado de Assis (1839-1908).

4 Existem discussões sobre a produção literária de Machado de Assis e de suas influências estrangeiras, porém não cabe aqui entrar nesse embate por não ser o foco no momento. Para aprofundar essa discussão, consultar o artigo de João Hernesto Weber do ano 2003, intitulado Machado: do discurso romântico da nacionalidade à crítica radical da nação. 
As trocas materiais de produtos e modos de fazer entre a cozinha portuguesa e a cozinha brasileira contribuem para a formação das identidades nacionais, posto que se encontram entrelaçadas - ora mais, ora menos nos processos políticos e econômicos dos dois países.

A afirmação de papel simultâneo de colonizador e colonizado de Portugal sustenta a análise sobre as relações estabelecidas entre o Brasil e o processo de independência e Primeira República. Portugal enquanto país colonizador, que ditava leis, normas e regras às suas colônias possuía status político de Império, dominante sobre o Brasil, este status passa a se transformar no século XIX, quando D. João VI transfere a corte para o Brasil, tendo a cidade do Rio de Janeiro como capital do império português.

Em meados do século XVIII, novas ideias começaram a surgir. O príncipe regente português, D. João $\mathrm{V}$, centralizou a política de 'colonização' de todo o vasto império que se estendia da América do Sul ao sul da Ásia. Seu objetivo era convencer não portugueses a se estabelecerem no Brasil e, em 1748, apenas dois anos antes de sua morte, ele empregou um agente incumbido de trazer milhares de açorianos daquelas superlotadas ilhas do Atlântico para o extremo sul do Brasil e para o Pará, na foz do Rio Amazonas ao norte. Esses planos lançaram apena um modesto sucesso, mas lançaram a base para os futuros planos de colonização patrocinados pelo Estado. (LESSER, 2015, p. 35, grifo do autor)

A mudança geográfica da capital do Império português para o Brasil passa a ditar também transformações políticas, econômicas e socioculturais, destacando o aumento da imigração entre os dois países e o aumento das movimentações financeiras e das atividades econômicas.

Mediante esses fluxos, as trocas culturais também se intensificam. Em relação aos hábitos e técnicas alimentares evidenciam-se a doçaria, seus saberes e fazeres, as confeitarias e os usos do chá.

O hábito de tomar chá foi introduzido pela família real e tornou-se uma instituição no Rio de Janeiro. Homens de letras, políticos e famílias em geral chegavam às confeitarias em grande número para o 'five o' clock tea', horário após o qual não era de bom tom às mulheres de fino trato permanecerem no recinto. (BELLUZZO, 2010, p. 92, grifo do autor) 
Partindo da discussão sobre os mitos da formação da nação brasileira, temos como base da alimentação a carne seca, o feijão e a farinha de mandioca, tríade básica presente desde a chegada dos portugueses ao Brasil, conforme descrições de viajantes que visitaram o país, como Saint-Hilaire (de 1816 a 1822) e Debret (1815), que relataram sobre uma mistura de cozinhas, de seus instrumentos, ingredientes e os modos de fazer. (SILVA, 2005)

As quitandeiras serviam angu com miúdos de carne de vaca, coração, fígado, bofe, língua, moela [...] E a esse prato acrescentavam folhas de nabo, pimentão verde ou amarelo, salsa, cebola, louro e tomates; tudo reduzido à consistência de um molho de boa liga. (DEBRET, 2000 apud BELLUZZO, 2010, p. 32)

O fato é que a cozinha brasileira é complexa e passa por diferentes movimentos históricos, sociais e econômicos. A influência africana na formação do gosto, na escolha de ingredientes e na constituição de pratos e receitas é amplamente discutida, mas com muitas divergências. A partir da discussão sobre os mitos da "invenção da brasilidade" (LESSER, 2015), é possível chegar à questão central sobre culturas étnicas e o racismo no Brasil.

À medida que o Brasil passava de colônia de Portugal (1500-1822) a império independente (1822-1889), para em seguida se tornar república (de 1889 até o presente), uma série de processos levaram à criação de uma sociedade pluralista, com uma hierarquia racial que colocava a branquidão no topo e a negritude na base. A fluidez desses termos e de seus significados, entretanto, fizeram com que o Brasil se tornasse uma nação multicultural, embora seus cidadãos geralmente vissem a si próprios e a seu país como se tornando progressivamente mais brancos. Termos como branco, negro, europeu, índio e asiático (entre outros) não tinham significado fixo no contexto brasileiro. Pessoas e grupos entravam e saíam dessas categorias sempre mutáveis, e a identidade nacional brasileira, era em geral, simultaneamente rígida (a branquidão era consistentemente valorizada) e flexível (o significado de branquidão era maleável). (LESSER, 2015, p. 38)

Essa é uma discussão muito importante que deve ser cuidadosamente estudada e abordada em momento oportuno, porém não deixo de ressaltar 
que esse debate é central para compreensão sistêmica da formação da cozinha e a formação de nação e de identidade nacional brasileira. Da mesma forma é de igual importância analisar a herança da culinária indígena, do cultivo e saberes acerca da alimentação. ${ }^{5}$

Nessa elaboração e formas de reconstruir um ethos brasileiro e formas de se alimentar, endente-se que a construção da culinária se torna mais evidente no período da independência e depois, da república.

A discussão sobre a formação nacional, inclusive de nossa culinária, pode ser situada entre 1870 e 1930, quando envolveu nos debates as elites econômicas e os intelectuais de todo o país. As cozinhas regionais emergiram como tema a partir de 1920, e de maneira mais forte no Nordeste. O segundo aspecto que merece menção é que, quando dizemos 'cozinhas regionais', em geral, estamos nos referindo, com maior ênfase, às cozinhas populares. Nesse ponto, têm pouca importância, por exemplo, os livros de culinária que expressam modas internacionais e atravessaram o Atlântico, influindo na prática culinária das grandes cidades da América. Temos também uma evolução distinta, marcada em primeiro lugar pela violenta liquidação da população nativa e pela direção dada à alimentação negra pelos colonizadores. Ao chegarmos à segunda metade do século XIX, as elites nacionais estavam mais sensíveis ao processo internacional de afrancesamento culinário do que a descoberta do que 'valeria a pena comer' e incorporar as suas vivências, escolhendo pratos em meio a um vasto e desorganizado repertório de comidas populares. (DÓRIA, 2014, p. 148, grifo do autor)

Ao ultrapassarmos essa ideia limitadora das três raças na formação da cultura brasileira é possível pensar nos processos políticos, sociais, econômicos e culturais que levaram aos discursos e teorias racistas do final do século XIX e início do XX, como as teorias evolucionistas de branqueado da população brasileira e as políticas de migração europeia

5 De certo é um assunto vasto que nos encaminha para várias direções e questões fundamentais na formação do Brasil. Não pretendo de maneira alguma dar conta de tudo, por ser claramente impossível tratar de assuntos tão complexos em apenas um capítulo. Entretanto, pontuo que a partir do debate em torno da comida e da cozinha é possível discutir diferentes aspectos sociais e marcadores de diferenças, como raça, gênero, classe, dentre outros temas clássicos das ciências sociais, que são evidenciados ao longo do texto. 
para cumprir tal função, podemos aprofundar os debates sobre as práticas culturais e no conceito de processo civilizador cunhado por Norbert Elias (2011) na tentativa de compreender os discursos acerca da identidade nacional no Brasil.

As identidades que começam a surgir da necessidade de reordenar territórios, de constituir uma nação forte e independente passa a ser um movimento estratégico de regimes políticos que os tomam como meio de unificar os países. Falamos um pouco sobre a formação de cozinhas a partir da relação Brasil e Portugal. Tentemos agora, relacioná-las com a literatura, com a eleição de dois grandes nomes: Eça de Queirós e Machado de Assis.

Em Portugal, como em toda a Europa, movimentos e manifestações nacionalistas ocorreram nesse período de afirmação dos estados nacionais. José Maria de Eça de Queirós (1845-1900) assume este papel de nacionalista enquanto uma personalidade pública, em que sua vida social, bem como suas obras, abrangem o contexto da sociedade portuguesa.

Suas obras clássicas - Os Maias e o Crime do Padre Amaro, por exemplo - são reconhecidas e estudadas também no Brasil. Sua inserção no campo da literatura brasileira ocorre não somente pela origem do idioma, mas também de sua aproximação com o país como jornalista e com as viagens e textos que estreitaram os laços políticos, sociais e culturais entre Brasil e Portugal. Eça dedicou-se à escola literária realista com descrições amplas e detalhadas dos acontecimentos cotidianos da realidade portuguesa, dentre eles, os hábitos alimentares e os modos à mesa portugueses.

Eça de Queirós pertencia à classe intelectual burguesa de Portugal, ocupou cargos públicos e obteve reconhecimento na literatura, preocupou-se em descrever e criticar a sociedade de seu tempo, sendo que o Brasil também fez parte dessas preocupações. "Falar do Brasil, para ele, seria uma maneira de se falar também de Portugal, Antonio Candido - numa perspectiva brasileira - mostra então os impactos do ficcionista português em sua geração, que teve atuação decisiva na formação do pensamento crítico de nosso país”. (ABDALA JÚNIOR, 2000, p. 10)

Eça de Queirós firmou no Brasil a imagem de um libertário: a denúncia do que havia de podre na realidade, valendo-se do manto diáfano da fantasia, de acordo com suas palavras. Essa imagem foi construída por sua obra de ficção e por suas colaborações jornalísticas. Elza Miné discute, nesse sentido, intervenções de 
Eça que foram decisivas na configuração dessa personalidade, em que os gestos do artista confluíam para o do cidadão. Nesse diálogo Brasil-Portugal ouve querelas, como a que envolveu Eça e Machado. (ABDALA JÚNIOR, 2000, p. 10)

Candido conta que Gilberto Freyre nos anos de 1930 distribuiu questionários para pessoas nascidas pouco antes ou pouco depois da Proclamação da República a fim de coletar dados sobre escola, esportes, moda, literatura e convicções dessa população para compor seu livro intitulado Ordem e Progresso. ${ }^{6}$ Dentre as respostas destacou-se uma rede nacional de apreço à Eça de Queirós estendendo-se por gerações. "Eça era tão lido e querido, que o sociólogo [Freyre] chega a incluí-lo entre os que contribuíram para a unidade intelectual do Brasil”. (CANDIDO, 2000, p. 11, grifo nosso)

Segundo estudiosos contemporâneos do autor, a cozinha descrita por Queirós é uma cozinha burguesa.

O texto mais exemplar e programático sobre o tema talvez seja o artigo conhecido como 'Cozinha Arqueológica', publicado em 1893, na Gazeta de Notícias. Nele, Eça afirmou: 'a mesa constituiu sempre um dos fortes, se não o mais forte alicerce das sociedades humanas' e 'O caráter de uma raça pode ser deduzido simplesmente de seu método de assar a carne' (III, p. 1226). A declaração ressalta a intrínseca relação entre comida e sociedade, que Eça reforça, ao adicionar: 'a cozinha e adega exercem uma tão larga e direta influência sobre o homem e a sociedade', por isso 'dize-me o que comes, dir-te-ei o que és' (III, p. 1226). (ANDRADE, 2015, p. 205, grifo do autor)

As obras e textos de Eça de Queirós são permeadas de descrições de pratos, jantares e banquetes que apontam os hábitos da época e as distinções sociais como marcadores de diferenças e construção de identidade, vindo ao encontro de estudos como os do próprio Elias $(2011)^{7}$ e os do antropólogo José Sobral (2007) que escreve sobre a cozinha portuguesa dividida a

6 Ordem e Progresso foi publicado originalmente em 1957. Para maiores informações consultar a obra de Freyre (2010).

7 Elias (2011) afirma que os modos de destrinchar a carne também é um aspecto do processo civilizador na sociedade de corte. Consultar a Parte IV Dos Modos à Mesa, presente no capítulo 2 (A civilização como transformação do comportamento humano). 
partir do contexto de classes, da cozinha burguesa, refinada e influenciada pelo processo civilizador da alta cozinha francesa e; da cozinha popular, rústica e simples, baseada nos hábitos regionais de pescadores e trabalhadores rurais do país.

As tramas de Eça de Queiroz em que aparecem trufas e ostras são cenários de luxo e requinte, onde tais alimentos - assim como também champanhes, Portos de determinada safra, produtos com excelência determinada pela referência geográfica, como as ostras de Marennes ou peixe da Dalmácia, ou pela raridade, chá de Naipó - aparecem como símbolo de distinção de classe, símbolos do gosto burguês. (SILVA, 2012, p. 29)

Eça tinha um grande interesse pelo Brasil pois via o país como uma extensão de Portugal devido o processo de colonização. Fato é que Eça nunca veio ao Brasil, mas conquistou a população brasileira de sua época a partir de seus escritos jornalísticos bem como suas obras literárias. O escritor português teve mais leitores aqui do que em seu país de origem. "Esse fato se explica pelo entrecruzamento das expectativas do escritor e seu público-leitor, entre estes e os mediadores críticos. Eça, republicano encontrava no Brasil formas de poder simbólico identificadas com o republicanismo que se respaldavam em esferas do poder político, fato que não ocorria em Portugal e sua monarquia decadente". (ABDALA JÚNIOR, 2000, p. 99)

Esse escritor fez-se tradição no Brasil, isto é, suas atitudes estético-literárias associaram-se a um habitus libertário, um modelo de pensamento-ação que sensibilizou a intelectualidade do país até a metade do século XX. Em algumas regiões brasileiras, como no Nordeste, sua produção soava subversiva mesmo nos anos da ditadura militar iniciada em 1964. O papel político de Eça no Brasil foi destacado por Paulo Cavalcanti, um dos mais entusiastas queirosianos brasileiros, em seu texto clássico Eça de Queirós, agitador no Brasil. (ABDLADA JÚNIOR, 2000, p. 100)

Abdala Júnior (2000) afirma que Eça era visto como escritor suspeito, inclusive no século XX como foi indicado acima, tanto em Portugal como no Brasil, um dos motivos era por defender ideais anti-imperialistas, 
influenciando autores brasileiros, como Graciliano Ramos, em relação às iniquidades da vida social brasileira.

$\mathrm{O}$ autor português criticou o discurso nacionalista conservador de Portugal e simpatizou com as políticas republicanas do Brasil. Em seu Brasil imaginário defendeu o brasileiro e sua identidade nacional, ainda que suas descrições eram por vezes limitadas e preconceituosas.

A carreira jornalística de Eça de Queirós no Brasil iniciou-se em 1880 na Gazeta de Notícias, com intervalos nas publicações entre 1883 e 1886, e um novo silêncio entre 1889 e 1991, retorna em janeiro de 1892 permanecendo até 1897.

O conjunto de matérias enviadas para o Rio de Janeiro constitui-se, assim, no que se pode considerar a obra jornalística de Eça de Queirós, pensada e elaborada tendo em vista o público brasileiro, por meio de um mesmo e único vínculo - a Gazeta de Notícias -. Este jornal desempenhou um papel de fundamental importância na impressa brasileira no último quartel do século XIX e início do século XX. (MINÉ, 2000, p. 43)

Miné (2000, p. 46) ainda diz que "em termos contemporâneos, poderíamos, sem dúvida, considerar Eça de Queirós um dos grandes “colunistas” da Gazeta de Notícias, notabilizando-se entre aqueles que, no Brasil, construíram essa espécie jornalística, com nível e brilho”.

No contexto brasileiro, Joaquim Maria de Machado de Assis, considerado um dos maiores escritores brasileiros, nasceu no Rio de Janeiro em 1839 e morreu em 1908, na cidade natal. Possui ampla obra literária em diversos estilos, dentre eles os contos e os romances, possui também textos de opinião pública sobre a conjuntura do país de sua época. (MAGALHÃES JÚNIOR, 2008)

Diferentemente de Eça de Queirós, Machado não se dedicou a grandes descrições acerca da alimentação ou das maneiras à mesa. Pelo contrário, criticou essas características na obra O Primo Basílio de Eça, afirmando ser exagero as descrições gastronômicas, vendo como um problema cultivado pela escola realista de literatura. (FANTINI, 2012)

Apesar de as obras de Machado não conter as riquezas de detalhes de pratos, costumes à mesa etc., mesmo que discretamente, os mencionou em seus trabalhos, e os apreciou em vida. Belluzzo (2010) descreve o seu apreço 
por boa comida e hábitos à mesa em suas visitas as padarias e confeitarias do Rio de Janeiro, uma clara influência da corte portuguesa no Brasil, ao mesmo tempo em que o autor reconhecia os contrastes do país, uma vez que Machado vivenciou, bem como analisou e foi um crítico de acontecimentos políticos importantes do país. "Foram momentos de efervescência social, sobretudo em virtude da abolição da escravatura”. (BELLUZZO, 2010, p. 83)

Dentre as importantes ocorrências dessa questão, a autora menciona alguns marcos importantes, como por exemplo, a proibição do tráfico negreiro em 1850, a Lei do Ventre Livre promulgada em 1871 e a própria Abolição em 1888, registrado por Machado no trecho da seguinte crônica.

Houve sol, e grande sol, naquele domingo de 1888, em que o Senado votou a lei, que a regente sancionou, e todos saímos à rua. Sim, também eu saí à rua, eu o mais encolhido dos caramujos, também eu entrei no préstito, em carruagem aberta [...]; todos respiravam felicidade, tudo era delírio. Verdadeiramente, foi o único dia de delírio público que me lembro ter visto. (ASSIS, 2008 p. 938 apud BELLUZZO, 2010, p. 83)

Ainda, é possível perceber que Machado se posicionou em defesa aos hábitos e costumes brasileiros no sentido tal de pensar questões sobre nacionalidades. Machado de Assis expressou sua visão política acerca da nação brasileira em diversos textos de modo subjetivo e como crítica social, ao defender que um escritor é fruto de seu tempo e espaço, o que expressa traços de um pertencimento nacional e de uma literatura que defende o nacionalismo. (FANTINI, 2012)

Machado apresenta pequenos lampejos sobre costumes alimentares como distinção social em alguns de seus romances, como no caso de Memórias Póstumas de Brás Cubas, em que o personagem principal mostra as distinções sociais nas relações entre senhores e escravos, na divisão da casa enquanto espaço privado, onde a cozinha praticamente faz parte da senzala e não das dependências em que seus proprietários circulam.

Ou ainda, quando se refere aos banquetes dos senhores descrevendo os aparelhos de jantar refinados, os talheres e castiçais de prata importados de Portugal. E, também, quando descreve sobre a confecção de doces em compota de frutos típicos do país, como o doce de coco, as marmeladas, o melado e o cará. (ASSIS, 1994) 
$\mathrm{O}$ autor também contribuiu em jornais e periódicos brasileiros, como por exemplo, Jornal das Famílias (1863), Ilustração Brasileira (1878), O Cruzeiro (1878); Gazeta de Notícias (1888 a 1893), Imprensa Fluminense (1888), escrevia sobre diferentes comportamentos, tendências e modismos que se passavam na metrópole, criticando a elite, mesmo participando dela.

A novidade dos restaurantes requintados atendia uma clientela seleta com 'menus' em francês que ofereciam magníficas ofertas de iguarias estrangeiras elaboradas com todo o esmero. Eram oásis gastronômicos que prosperaram, porém ficavam restritos a um público europeizado e exigentes. Porém, como Machado bem sabia, o 'banquete da vida', fosse ele habitado por iguarias nacionais ou estrangeiras, nem sempre era 'uma delícia' para seus contemporâneos. A grande maioria da população livre e dos escravos alimentavam-se de feijão, carne seca, farinha de mandioca, pirão e angu, comida essa que não experimentou quaisquer aperfeiçoamento e os requintes granjeados pelas mesas mais favorecidas, ao longo de praticamente todo o século XIX e início da jovem República. (BELLUZZO, 2010, p. 144, grifo do autor)

Podemos perceber que Machado de Assis foi um crítico da sociedade brasileira e como homem de seu tempo preocupou-se em compreender o processo histórico ao qual estava inserido e, ainda que compartilhasse de uma posição privilegiada, mantendo um status social elevado, frequentando teatros, confeitarias e restaurantes de preços elevados e pouco acessíveis. $\mathrm{O}$ autor tinha consciências das desigualdades sociais do Brasil e contribuiu para a construção da crítica de determinados comportamentos e tendências adotados na sociedade brasileira.

A aparente opulência representada pela sofisticação dos costumes gastronômicos das elites não atenuou (nem poderia fazê-lo) a melancolia machadiana, ou seja, ela em relação à condição humana em geral, seja ela em relação à situação social do Brasil. Com esse pano de fundo, talvez a típica reação de Machado de Assis aos feéricos cardápios que presenciou fosse a de 'ajuntar os restos de festim, mandar fazer o que a arte culinária chama roupa velha, e comê-la com os amigos, sem vinho'. (ASSIS, 2008, p. 948 apud BELLUZZO, 2010, p. 144, grifo do autor) 
Compreende-se que o processo de construção do discurso sobre identidade ou cultura brasileira pode partir de duas situações: do campo científico para o senso comum; ou do senso comum para o campo científico; “ $[. .$.$] o$ importante a ressaltar é a interação entre cultura erudita e cultura popular e a circulação de ideias”. (OLIVEN, 1989 apud OLIVEN, 2002, p. 16)

Ainda, conforme Mintz (2003), as comidas de um país são antes que nacionais, regionais. Isso é fato, tanto no Brasil quanto em Portugal, pois são nas localidades e nas regiões que o cotidiano transcorre e se desenvolve e, consequentemente, formam no regional o que lhes é nacional.

Machado e Eça foram contemporâneos e em várias circunstâncias suas vidas e obras se entrecruzaram, com críticas de um a outro, de posicionamentos sobre a política e a literatura. Os autores como homens de seu tempo, vivenciando a conjuntura histórica e cultural do Ocidente sobre a consolidação dos Estados-nações e suas expressões nacionalistas perante o resto do mundo para travar disputas entre poderes políticos, econômicos e culturais.

Os dois autores traçaram uma trajetória pública para além do ofício de escritor com envolvimento político e opiniōes sobre os projetos nacionais. A relação entre eles não era harmoniosa, trocavam duras críticas.

Um dos grandes agentes a aquecer o polêmico cenário do nosso jornalismo oitocentista é o escritor português Eça de Queirós, que, do outro lado do Atlântico, colabora em periódicos brasileiros. Nesse contexto, irrompe um clima de mal-estar entre Eça e Machado de Assis, quando este decide responder de viés ao que acredita ser um desrespeitoso motejo daquele em relação aos brasileiros em geral, ao imperador do Brasil e, particularmente, ao próprio Machado. (FANTINI, 2012, p. 113)

Machado e Eça debatiam opiniões e publicavam suas provocações e suas respectivas respostas nos jornais brasileiros, indicando uma disputa por legitimidade de expressão no e sobre o país, de suas representações, de suas condutas políticas e formação do estado brasileiro e sua literatura. As críticas vinham desde os estilos de escrita de um e de outro, bem como de posicionamentos políticos. Dentre eles, a formação do Brasil e do povo brasileiro. Eça em determinados textos e contextos inferiorizou o Brasil e os brasileiros com insultos ao imperador e ao próprio Machado. 
As trocas de informações eram intensas nesse momento de transição de império para república. Assim também o era nas trocas materiais, de produtos e modos de fazer entre a cozinha portuguesa e a cozinha brasileira contribuindo também para a formação das identidades nacionais, posto que se encontram entrelaçadas - ora mais, ora menos - nos processos políticos e econômicos dos dois países. Braga (2010) aponta para o desenvolvimento desse tipo de comércio em Portugal e da sua aceitabilidade por parte dos portugueses.

Sabendo-se que, à medida que os portugueses se foram fixando no Brasil, levaram seus hábitos e costumes alimentares, mas que estes tiveram que ser adaptados à realidade do novo espaço, não é de se estranhar que a trilogia alimentar no Brasil colonial tenha sido diferente. Isto é, à metropolitana carne, pão e vinho contrapõe-se a colonial carne (seca), feijão e mandioca. Se, por regra, se pode destacar abundância de carne (verde ${ }^{8}$ ou seca), de peixe (fresco ou seco) e, sobretudo, de frutas, não é menos verdade que tais alimentos não chegavam a todos e que o Rio de Janeiro era um espaço bastante bem abastecido. (BRAGA, 2010, p. 167)

\section{DINÂMICAS CULTURAIS E FORMAÇÃO DAS COZINHAS DE BRASIL E DE PORTUGAL}

Traçar a formação da identidade nacional e aspectos da civilização brasileira por meio do estabelecimento de sua cozinha, na escolha, por vezes arbitrárias e outras por interesses políticos e econômicos, de produtos, ingredientes e de pratos típicos, torna-se possível entender a cozinha como elemento cultural e político na construção de identidades nacionais. A culinária pode ser duplamente considerada como marcador de identidades, tanto para o discurso oficial quanto para as vivências cotidianas de pessoas comuns. É um dos elementos em que cozinhas, receitas, pratos são classificados como nacionais para legitimar um país, um governo ou diferentes tipos de

8 Carne verde é uma expressão utilizada em Portugal, mas também no Brasil - sobretudo em textos do século XIX e início do século XX - para referir-se à carne fresca in natura. 
interesses, como de unificação, ou até mesmo separação de territórios. Ao mesmo tempo em que é um dos aspectos mais fortes em relação ao reconhecimento e pertencimento de um grupo.

Os traços de aproximações das construções de identidades nacionais entre os dois países são acentuados por meio dos hábitos e costumes regionais. (OLIVEN, 2002) No caso de Portugal, José Manuel Sobral (2007) ao analisar o histórico das receitas e dos produtos utilizados para a confecção de pratos típicos, relacionando-os às observações de campo que realizou em um festival de comidas típicas na região de Ribatejo, ${ }^{9}$ percebe dois principais contrastes das regularidades regionais: o primeiro trata-se dos elementos utilizados na região litorânea do país, relacionados à pesca e aos elementos utilizados no mundo agrícola; e o segundo contraste seria o das diferenças e oposições entre norte e sul do país. Assim, o autor percebe que o Festival é "[...] uma festa que exalta as especificidades regionais constitutivas do todo nacional”, e define (assim como Oliven (2002) aponta no caso brasileiro) que nessa situação "o nacional é o regional”. (SOBRAL, 2007, p. 25)

No Festival os aspectos regionais são representados pelos elementos que constituem o universo rural e os que constituem o universo da pesca em Portugal, que atualmente encontra-se em declínio e, em alguns casos, até mesmo desapareceu.

Os símbolos escolhidos para representar o país no Festival são os mesmos símbolos que foram utilizados nos projetos nacionais do Estado Novo de Portugal. ${ }^{10}$ Por sua vez, o Estado Novo utilizou-se dessas representações que serviram como dispositivo para legitimar uma identidade nacional, propondo no discurso oficial identificar uma cultura nacional genuína junto às massas populares.

Essas representações referiam-se aos trabalhos desenvolvidos nas zonas rurais e marítimas, como a agricultura e a pesca, importantes para a economia do país pré-industrial do século XIX, exaltando os trabalhos manuais, o artesanato e os saberes tradicionais das regiões, relacionando-as à ideia de nação, de um país unificado e majoritariamente rural.

9 Trata-se do XXIV Festival Nacional de Gastronomia, que teve lugar em Santarém em 2004, estudado por Sobral (2007) na busca por compreensão do processo de formação da identidade portuguesa e da cozinha nacional.

10 O Estado Novo foi em Portugal um regime político autoritário de cunho nacionalista e corporativista, de inspiração fascista, liderado por António Oliveira Salazar e durou 41 anos, entre os anos de 1933 a 1974. 
Para compreender esses elementos que foram selecionados para representar o país oficialmente, Sobral (2007) retoma a história do país e da Europa para analisar o contexto do período e as dinâmicas desse movimento. Por meio da literatura e outras fontes históricas, o autor identifica a predominância do uso e apropriação da cozinha francesa na sociedade de corte portuguesa, desde os cardápios e serviços até os costumes apresentados nas festas e jantares oficiais.

Sobral (2007) faz um comparativo entre os menus oficiais do século XIX e os menus oferecidos no Festival de Santarém, em que ambos demonstram uma situação de contraste extremo com a exaltação do nacional e do regional. Os cardápios do século XIX evidenciavam as diferenças entre cozinha de rico e cozinha de pobre, assim, mais que a defesa de uma nacionalidade, esses cardápios abrigam uma manutenção dos status quo por meio da distinção social.

A cozinha francesa predominava nas classes dominantes portuguesas representativas de um processo civilizador, mas a cozinha regional era enaltecida em determinados eventos sociais para demarcar as especificidades do português por meio de seus hábitos alimentares. Aos ricos recomendava-se a cozinha internacional, aos pobres a cozinha nacional - composta pelos elementos regionais da classe rural trabalhadora.

José Sobral (2007) demonstra claramente que a cozinha nacional portuguesa fora designada como comida de rico e, por sua vez, a comida regional como comida de pobre. Esse é um dos principais aspectos que a formação das duas cozinhas se aproxima e se inter-relaciona. Como já apontado no início do capítulo, no Brasil acontece de modo muito semelhante, onde a cozinha regional brasileira é entendida como cozinhas populares, enquanto a nacional se relaciona com as influências das cozinhas internacionais, especialmente por meio dos finos restaurantes dos hotéis que eram frequentados pela burguesia brasileira. (DÓRIA, 2014; BELLUZZO, 2010)

No caso brasileiro, o sentimento nacionalista intensificou-se na sociedade principalmente no período da a regência do príncipe D. Pedro I, após D. João VI e sua corte deixar o país em 1821. O fim da monarquia e o início do império brasileiro e as lutas políticas de D. Pedro por uma constituição parece ter contribuído para o início da conscientização do Brasil enquanto Estado-nação, deixando de ser colônia para ser autônomo, ainda que no comando de um português. 
Assim, podemos entender que a Independência do Brasil seria o resultado de um processo anterior, já iniciado em 1822. "É em torno da figura de Pedro II que em muito se personificou a unidade do Estado Nacional, assim como a responsabilidade de introdução da modernidade no país, o projeto iluminista que integra o Brasil à cultura ocidental, ao mundo civilizado”. (DUTRA, 2004, p. 95)

Entretanto, segundo diversos historiadores, não houve participação popular nesse movimento e a legitimidade do novo regime político começa a ser viabilizada com a elite política dos grandes estados em ascensão São Paulo, Minas Gerais e Rio Grande do Sul -, instaurando-se a república oligárquica a partir do modelo federativo (DUTRA, 2004), que já vinha sendo reivindicado desde o império.

Tendo em vista que a constituição da nação enquanto uma instituição é relativamente nova no processo histórico da sociedade ocidental, datando pouco mais de duzentos anos, "[...] ela pressupõe a existência de cidadãos com direitos igualitários, de uma sociedade secularizada, com instituições independentes e desenvolvidas. No Brasil, como nos demais países da América Latina, em sua gênese, nação e modernidade caminham juntas”. (OLIVEN, 2002, p. 17)

No século XIX Machado de Assis já havia se ocupado da questão da nacionalidade na literatura brasileira. Em um ensaio publicado em 1837, embora reconhecesse a legitimidade de um 'instinto de nacionalidade' por parte da literatura da então jovem nação brasileira, ele argumentava que não se devia carregar no uso do local sob o risco de restringir a compreensão das obras a um grupo muito restrito. Para Machado, 'um poeta não é nacional só porque insere nos seus versos muitos nomes de flores ou aves do país, o que pode dar uma nacionalidade ao vocabulário e nada mais'. (OLIVEN, 2002, p. 20, grifo do autor)

Essa discussão sobre o que é ser brasileiro e a valorização da pátria é retomada de modo mais explícito na semana modernista de 1922, que representa a busca pela nacionalidade brasileira valorizando sua cultura, partindo da afirmação de brasilidade.

Oliven (2002) retoma os preceitos da Semana da Arte Moderna de 22 com o ideal nacionalista na busca pelo reconhecimento universal, contrapondo-os com o Manifesto Regionalista iniciado por Gilberto Freyre em 1926, que partia da valorização dos costumes e tradições regionais. 
No manifesto é possível encontrar a preocupação da manutenção das tradições, inclusive as culinárias, cujo autor afirmou: “[...] uma cozinha em crise significa uma civilização inteira em perigo, o perigo de descaracterizar-se”. (FREYRE, 1976, p. 76 apud OLIVEN, 2002, p. 28)

É neste período, entre guerras, que mudanças ocorrem e instigam novas reflexões sobre o país, que passava por uma consolidação política e enfrentava crises consequentes da quebra da bolsa de Nova York (1929) e, precedia a Segunda Guerra Mundial (1939). Neste momento, “o nacionalismo ganha ímpeto e o Estado se firma”. (OLIVEN, 2002, p. 31)

Desde a Independência do Brasil, passando pelos diferentes momentos históricos e as mudanças políticas, o pensamento social brasileiro é constituído de tais questões, ora enaltecendo o nacional, ora o regional, mas sempre com a perspectiva da construção e reconhecimento da nação e da construção da identidade brasileira.

Assumindo essas características torna-se mais evidente o processo de formação da cozinha brasileira que varia e privilegia ora os elementos nacionais ora os elementos regionais, dependendo dos interesses políticos e econômicos, bem como dos movimentos culturais e sociais do momento histórico em questão.

A alimentação como problema central da questão nacional está presente no Brasil pelo menos desde a Primeira República, em que se via a fome e a pobreza como um problema social. Já no século XX, após a Revolução de 1930 em que se constitui a Era Vargas, se tem um projeto político-pedagógico para a construção da nação pensando a nutrição no cenário mundial por meio da ciência. Josué de Castro aproxima-se do discurso sanitarista desenvolvimentista, em que reconhece a questão da fome como um problema de saúde pública.

O projeto civilizatório nacional configurado no modelo explicativo-causal e nas medidas saneadoras da fome e do atraso brasileiros, presentes nessas ideias veiculadas pelo INUB, teria por premissa uma reforma social orientada pela ciência e liderada pelo Estado, na qual progressismo, patriotismo e política alimentar convergiriam em um investimento no homem, para remoção dos obstáculos ao nation and state building erguendo a nacionalidade e redimindo-a do atrasa. E inscrevendo o Brasil na civilização não mais da comida bárbara, mas da alimentação pública. (BIZO; LIMA, 2010, p. 204-205, grifo do autor) 
Nesse ideal de nação, "de acordo com os autores, sendo a "subalimentação nacional" o principal e mais complexo problema do país, representaria um desvio aos dirigentes e requeria urgente solução”. (BIZO; LIMA, 2010, p. 198) Nesta máxima, superar a fome, superaria o barbarismo e elevaria a civilização da nação, uma vez que a fome traz subnutrição e com ela doenças, conflitos sociais, derrotas políticas e militares. A fome, portanto, afetaria a condição nacional como um país de fome, ou seja, uma sub nação.

Neste período o projeto nacional preocupa-se no reconhecimento do país por suas glórias e beneficies, eliminando-se problemas tidos como particulares de países de "terceiro mundo" e não desenvolvidos.

\section{CONSIDERAÇÕES FINAIS}

"O comportamento relativo à comida liga-se diretamente ao sentido de nós mesmos e à nossa identidade social, e isso parece valer para todos os seres humanos”. (MINTZ, 2001, p. 31) Os hábitos alimentares no Brasil passam por mudanças significativas após a instalação da corte portuguesa no Rio de Janeiro com a inserção de diferentes ingredientes e de novos modos de fazer e de comer. As transformações dos costumes à mesa, de socialização e do fluxo de portugueses e brasileiros, trazem transformações políticas e sociais importantes, assim como reflexões acerca das identidades coletivas de quem nasceu brasileiro e de quem escolheu o país como nova morada.

O final do século XVIII e início do XIX é muito representativo na construção de sentimentos relacionados à brasilidade e ao significado do que é ser brasileiro, que perpassam questões políticas e culturais entre Brasil e Portugal, indo além das questões internas, como por exemplo, do processo de independência do país.

As trocas simbólicas e materiais entre os dois países são dinâmicas importantes e chave de explicação para o entendimento da formação da nação brasileira.

A definição gradativa do território, a formação de uma mentalidade luso-brasileira e o sentimento de independência caracterizaram um sentido mais acentuado de nacionalidade do que o próprio processo de independência. Marcado por fatores externos relacionados à vida política europeia, o processo de independência, na realidade, pouco contribuiu para a construção do sentimento nacional. (OLIVEIRA, 1990, p. 77) 
Representantes do pensamento social desse período, como Eça de Queirós e Machado de Assis demonstraram por meio de seus artigos (científicos e de opinião) a formação de um sentimento e de um discurso nacional que apontavam para as particularidades de suas nações, que perpassavam por elementos e fenômenos desde o âmbito privado, dos hábitos e costumes cotidianos, até o âmbito público, das políticas públicas e normativas instauradas para consolidar seus projetos nacionais.

É fato que o período destacado neste artigo designado como Primeiro Império até a constituição da Primeira República, passando por todo o processo de Independência do Brasil é um dos momentos cruciais para a formação da identidade nacional, da demarcação de fronteiras, reconhecimento das diferenças culturais e, consequentemente, da formação do que se entende hoje por culinária ou cozinha brasileira.

Um período de efervescência política, econômica, social e cultural que demarca o processo civilizador do Brasil, da constituição do caráter nacional, dos marcadores sociais da diferença, dos status quo do país. Um momento em que as migrações se intensificaram e com isso as trocas materiais e imateriais que contribuíram para pensar ou "inventar" a brasilidade a partir da formação de identidade nacional, etnicidade e políticas de imigração. (LESSER, 2015)

Tratando especificamente da formação da cozinha brasileira temos nesse período o desenvolvimento de certas práticas que seguiram o fluxo do mundo do trabalho e das convenções sociais que se estabilizavam conforme o país crescia em número de habitantes e de estrangeiros que aqui se acomodavam. "O hábito de comer fora de casa foi imposto aos segmentos sociais de baixa renda devido ao horário de trabalho das casas comerciais, que encerrava seu expediente às 22 horas”. (BELLUZZO, 2010, p. 67)

Nesse sentido diferentes estabelecimentos começaram a surgir para suprir essa demanda. "Os portugueses ofereciam opções populares, como tavernas, botequins e casas de pasto, ${ }^{11}$ em geral frequentados por funcionários públicos, operários, caixeiros e pequenos comerciantes”. (BELLUZZO, 2010, p. 67)

11 Segundo Belluzzo (2010) as tavernas e botequins eram um tipo de armazém que vendiam bebidas alcoólicas, como vinho e cachaças e petiscos e comidas caseiras com preços acessíveis. Já as casas de pasto serviam dois tipos de refeições mais elaboradas e mais custosas: o prato de colher - constituídos de ensopados, guisados e angus - e o prato de garfo, com meu fixo e pratos mais leves e refinados acompanhados de meia garrafa de vinho. 
Além desses havia restaurantes mais sofisticados, mais comumente situados em hotéis recém estabelecidos no Brasil seguindo os moldes da gastronomia francesa e, portanto, da profissionalização das práticas de cozinha.

\begin{abstract}
Enquanto franceses e italianos predominavam nos restaurantes e confeitarias, a cozinha portuguesa permanecia nas tavernas, nos botequins e casas de pasto. Aí eram servidos caldos verdes, caldeirada de peixe, bife a cavalo, bacalhau à lagareira ou à moda do Porto, sardinhas, olla podrida (depois denominada 'cozido carioca') e galinha à cabidela. (BELLUZZO, 2010, p. 93 grifo do autor)
\end{abstract}

Mediante essa explanação e, seguindo os relatos históricos de Rosa Belluzzo (2010) percebemos que há dois movimentos em relação à culinária, primeiro o já discutido movimento regionalista que preza as especificidades das regiões ao que diz respeito aos hábitos alimentares, não só no uso de ingredientes, mas, também, nos modos de preparo, nas tradições regionais que foram sendo constituída a partir de uma culinária popular, do cotidiano; e em segundo, o movimento nacionalista, que busca uma universalidade no sistema alimentar do Brasil, caracterizando determinados pratos, como por exemplo, a tão discutida feijoada, ${ }^{12}$ como prato tipicamente nacional, que busca modos de fazer mais elaborados, sofisticados, que demandam técnicas e saberes profissionais, apontando para um processo civilizador do país, na qualificação profissional, na constituição de um habitus $^{13}$ (ELIAS, 2011) e costumes moldados a uma classe dominante do país, assumindo um discurso oficial.

Os dois movimentos - tanto no Brasil quanto em Portugal - contribuem para a compreensão da formação das cozinhas e das identidades nacionais, que se aproximam no modus operandi de se relacionar com a comida e desenvolver uma cultura alimentar ampla e complexa.

12 A feijoada enquanto prato típico brasileiro é discutida por diferentes autores que trazem diferentes perspectivas e historicidades em sua constituição. Para mais detalhes sugiro consultar as já presentes referências Belluzzo (2010) e Dória (2014) e, para aprofundar no assunto consultar o livro A vitória da feijoada de 2012 do historiador Almir Chaiban El-Kareh.

13 Utilizo aqui o conceito de habitus cunhado em 1933 por Norbert Elias em seu livro O processo civilizador, em que é compreendido como um aspecto consequente do processo civilizador da sociedade ocidental, cuja gênese está no que o autor chama de Sociedade de Corte, onde aspectos da vida individual e da social foram se moldando conforme ideias e práticas específicas de autocontrole e controle dos afetos que vão sendo elaborados, transformados e sofisticados em um longo processo histórico. 
No esforço aqui realizado de pensar acerca do tema das trocas culturais e materiais na alimentação entre Brasil e Portugal e suas contribuições para formação de identidades nacionais, podemos, ainda que de maneira superficial, indicar mais proximidades do que se mostra inicialmente entre as duas nações. Portugal tem o papel de civilizador no processo de desenvolvimento da nação brasileira, porém invertido ao longo dos entrelaçamentos culturais e políticos com o Brasil. Aponto isto não apenas no campo da alimentação, mas sobretudo, dos significados e representações de que cada ingrediente, prato e saberes trazem para o campo das identidades coletivas e de que maneira elas são impressas no cotidiano brasileiro e no discurso oficial a fim de legitimar o país enquanto Estado-nação.

\section{REFERÊNCIAS}

ABDALA JÚNIOR, B. Ecos do Brasil: Eça de Queirós, leituras brasileiras e portuguesas. São Paulo: SENAC São Paulo, 2000.

ANDERSON, B. Comunidades imaginadas: reflexões sobre a origem e a difusão do nacionalismo. São Paulo: Companhia das Letras, 2008.

ANDRADE, J. R. Gula e literatura: diálogo gastronômico com a obra de Eça de Queirós. Revista Desassossego, São Paulo, v. 7, n. 14, p. 204-2018, 2015. Disponível em: https://www.revistas.usp.br/desassossego/article/view/90834. Acesso em: 18 abr. 2017.

ASSIS, J. M. M. Memórias Póstumas de Brás Cubas. Rio de Janeiro: Editora Nova Aguilar, 1994.

BELLUZZO, R. Machado de Assis: relíquias culinárias. São Paulo: Ed. UNESP, 2010.

BIZO, M. L. G.; LIMA, N. T. O projeto civilizatório nacional do Instituto de Nutrição da Universidade do Brasil (1946-1960). Perspectivas, São Paulo, v. 37, p. 191-209, 2010. Disponível em: https://periodicos.fclar.unesp.br/perspectivas/article/ view/3558. Acesso em: 23 out 2017.

BRAGA, I. M. R. M. D. Sabores do Brasil em Portugal: descobrir e transformar novos alimentos (séculos XVI-XXI). São Paulo: Editora Senac São Paulo, 2010.

CANDIDO, A. Eça de Queirós, passado e presente. In: ABDALA JÚNIOR, B. Ecos do Brasil: Eça de Queirós, leituras brasileiras e portuguesas. São Paulo: SENAC São Paulo, 2000.

DAMATTA, R. O que faz o brasil, Brasil?. 5. ed. Rio de Janeiro: Rocco, 1991.

DÓRIA, C. A. Formação da culinária brasileira: escritos sobre a cozinha inzoneira.

São Paulo: Três Estrelas, 2014. 
DUTRA, R. C. A. Nação, região, cidadania: a construção das cozinhas regionais no Projeto Nacional Brasileiro. Campos, Curitiba, v. 5, n. 1, p. 93-110, 2004.

ELIAS, N. O processo civilizador. 2. ed. Rio de Janeiro: Zahar, 2011.

FANTINI, M. Recepção de Eça de Queirós por Machado de Assis. Letras, Santa Maria, v. 2, n. 45, p. 111-125, 2012. Disponível em: https://periodicos.ufsm.br/ letras/article/view/12209. Acesso em: 18 abr. 2017.

FREYRE, G. Ordem e Progresso. 6. ed. São Paulo: Global, 2010.

HALL, S. A identidade cultural na pós-modernidade. 9. ed. Rio de Janeiro: DP\&A, 2004

LESSER, J. A invenção da brasilidade: identidade nacional, etnicidade e políticas de imigração. São Paulo: Editora Unesp, 2015.

MAGALHÃES JÚNIOR, R. Vida e obra de Machado de Assis: aprendizado. São Paulo: Record, 2008.

MINÉ, E. Eça jornalista no Brasil. In: ABDALA JÚNIOR, B. Ecos do Brasil: Eça de Queirós, leituras brasileiras e portuguesas. São Paulo: SENAC São Paulo, 2000.

MINTZ, S. W. O poder do doce e a doçura do poder. In: MINTZ, S.; DABAT, C, R. (org.). O poder amargo do açúcar: produtores escravizados, consumidores proletarizados. Recife: Editora Universitária da UFPE, 2003. p. 171-193.

MINTZ, S. W. Comida e antropologia: uma breve revisão. Revista Brasileira de Ciências Sociais, São Paulo, v. 16, n. 47, p. 31-178, 2001. Disponível em: http:// www.scielo.br/pdf/rbcsoc/v16n47/7718.pdf. Acesso em: 28 out. 2011.

OLIVEIRA, L. L. A questão nacional na Primeira República. São Paulo: Brasiliense, 1990.

OLIVEN, R. G. Cultura brasileira e identidade nacional (o eterno retorno). In: MICELI, S. O que ler na ciência social brasileira. São Paulo: ANPOCS: Editora Sumaré, 2002. p. 15-43.

PEIRANO, M. G. S. Antropólogos e suas linhagens. Brasília, DF: UnB, 1990. (Série Antropologia). Disponível em: http://vsites.unb.br/ics/dan/Serie102empdf.pdf. Acesso em: 7 maio 2008.

SILVA, M. C. M. Eça de Queiroz e a cozinha burguesa: literatura e alimentação. 2012. Dissertação (Mestrado em Ciências Sociais) - Universidade Federal do Rio Grande do Norte, Natal, 2012.

SILVA, P. P. Farinha, feijão e carne-seca: um tripé culinário no Brasil colonial. 2. ed. São Paulo: SENAC São Paulo, 2005. 
SOBRAL, J. M. Nacionalismo, culinária e classe: a cozinha portuguesa da obscuridade à consagração (século XIX-XX). RURIS, Campinas, v. 1, n. 2, p. 13-52, 2007. Disponível em: https://www.ifch.unicamp.br/ojs/index.php/ruris/article/ view/651. Acesso em: 1 ago. 2018.

WEBER, J. H. Machado: do discurso romântico da nacionalidade à crítica radical da nção. Machado de Assis em linha, Rio de Janeiro. v. 6, n. 12, p. 32-45, 2013. Disponível em: http://www.scielo.br/scielo.php?script=sci_arttext\&pid=S19836821 $2013000200004 \& \operatorname{lng}=$ en\&nrm=iso\&tlng=pt. Acesso em: 12 out. 2018. 